\title{
Superinnervation Enhances the Dendritic Branching Pattern of the Mauthner Cell in the Developing Axolotl
}

\author{
Linda A. Goodman and Pat G. Model \\ Department of Neuroscience, Rose F. Kennedy Center for Research in Mental Retardation and Human Development, \\ Albert Einstein College of Medicine, Bronx, New York 10461
}

Mauthner cells (M-cells) occur as a pair of large, uniquely identifiable neurons at ear level in the hindbrain of premetamorphic amphibians. Each receives synapses from the ipsilateral vestibular nerve (nVIII); these morphologically distinctive terminals, or club endings, are confined to the proximoventral surface and branches of the M-cell lateral dendrite. We have superinnervated this portion of the $\mathbf{M}$-cell to examine the extent to which forming afferent contacts regulate the growth and branching of the lateral dendrite. Superinnervation was brought about in the developing axolotl (Ambystoma mexicanum) by unilaterally implanting an extra vestibular primordium rostral to the in situ one. The contralateral side served as control. When the larvae reached $21 \mathrm{~mm}$ in length, the ectopic nerve was labeled with HRP. Subsequent microscopic examination revealed that the grafts developed into anatomically normal ears. The HRP-labeled ectopic axons entered the medulla at the level of $\mathrm{nV}$ and confined to the nVIII tract, coursed caudad toward the ipsilateral $\mathrm{M}$-cell. Electron microscopic analysis demonstrated labeled club endings on the appropriate region of the M-cell lateral dendrite. The number of club endings on experimental $M$-cells was significantly greater than that on the contralateral controls, and the extra terminals appeared to be distributed randomly among unlabeled ones. Comparison of reconstructed experimental and control M-cells revealed that superinnervation produced a localized enhancement of dendritic branching in the region receiving the extra nVIII synapses. In the donor embryos (those from which the vestibular primordium was removed), M-cells were unilaterally deprived of $\mathrm{nVIII}$ afferents. Comparison of reconstructed experimental and control M-cells in $21 \mathrm{~mm}$ donor larvae demonstrated that deprivation produced a localized decrease of dendritic surface in the region that normally receives $\mathrm{nVIII}$ synapses. Together, these data show that ingrowing axons stimulate dendritic growth and thus regulate the development of a normal dendritic branching pattern on target neurons.

\footnotetext{
Received Mar. 18, 1987; revised July 21, 1987; accepted Sept. 10, 1987

We wish to thank Sarah Wurzelmann for her expert preparation of publication prints and Kathleen Tinglin for her fine technical assistance. The work reported here is from a thesis to be submitted in partial fulfillment of the requirements for the Degree of Doctor of Philosophy in the Sue Golding Graduate Division of Medical Sciences, Albert Einstein College of Medicine, Yeshiva University. 'This work was supported in part by NIH Training Grant T32GM7288 and by U.S. Public Health Service Grant NS-18823.

Correspondence should be addressed to Linda A. Goodman, Department of Neuroscience, Rose F. Kennedy Center, Box 33, Albert Einstein College of Medicine, 1410 Pelham Parkway South, Bronx, NY 10461

Copyright (C) 1988 Society for Neuroscience $0270-6474 / 88 / 030776-16 \$ 02.00 / 0$
}

Different classes of neurons may have radically different appearances: the morphology of the dendritic branching pattern is often the most characteristic feature of a distinct neuronal type. The development of normal branching patterns is essential to proper neuronal function in the mature nervous system. The observation that dendritic development proceeds in conjunction with the ingrowth of axons and formation of terminal contacts suggests that afferent innervation stimulates the differentiation of postsynaptic dendritic structures (Morest, 1969; Rakic, 1972). Accumulating evidence (e.g., Rakic and Sidman, 1973) supports this hypothesis: afferent innervation appears to be required by target neurons for the complete development of their dendritic arborizations. Deafferentation early in the postembryonic period inhibits or slows further growth (Larsell, 1931; Murphey et al., 1975) or produces atrophy (Benes et al., 1977) of postsynaptic dendrites. When a source of afferent innervation is removed from a developing embryo prior to axonal outgrowth, the development of target neurons is also altered: reduced dendritic branching patterns (Altman and Anderson, 1972; Kimmel et al., 1977; Parks, 1981), small neurons (Levi-Montalcini, 1949; Parks, 1979), and neuronal degeneration (Levi-Montalcini, 1949; Peusner and Morest, 1977; Parks, 1979) have been reported. While the data support the hypothesis that dendritic development depends on afferent input, they constitute only indirect evidence of a stimulating effect, and the approach precludes the possibility of investigating the mechanisms of transsynaptic stimulation and of identifying tropic agents that may mediate the effect.

We have studied the effects imposed by ingrowing axons on dendritic growth by superinnervating an identified target neuron, the Mauthner cell (M-cell). M-cells occur as a single pair of interneurons that are located in the medullae of premetamorphic amphibians and fish at the level of entry of the vestibular nerve (Herrick, 1914; Bartelmez, 1915, respectively). $\mathrm{M}$-cells are the largest neurons in the brain of the axolotl ( $\mathrm{Am}$ bystoma mexicanum). As in other species, its M-cell is an integral component of the neural circuit responsible for the escape reflex: the $\mathrm{M}$-cell axon terminates on the contralateral motoneurons that innervate the axial musculature and thus controls tail flips. A bipolar morphology is characteristic of the axolotl M-cell: it has a very large lateral dendrite and a large medial one. Both dendrites give rise to higher-order dendritic branches. The axon originates at the proximodorsal border of the medial dendrite. M-cells are found at the interface between the gray and white matters; their long axes are oriented almost perpendicular to the long axis of the CNS (Fig. 1, $A, B$ ). Afferent terminals have a regional organization on the surface of the M-cell (in fish, Bartelmez, 1915; Bodian, 1937; and in amphib- 


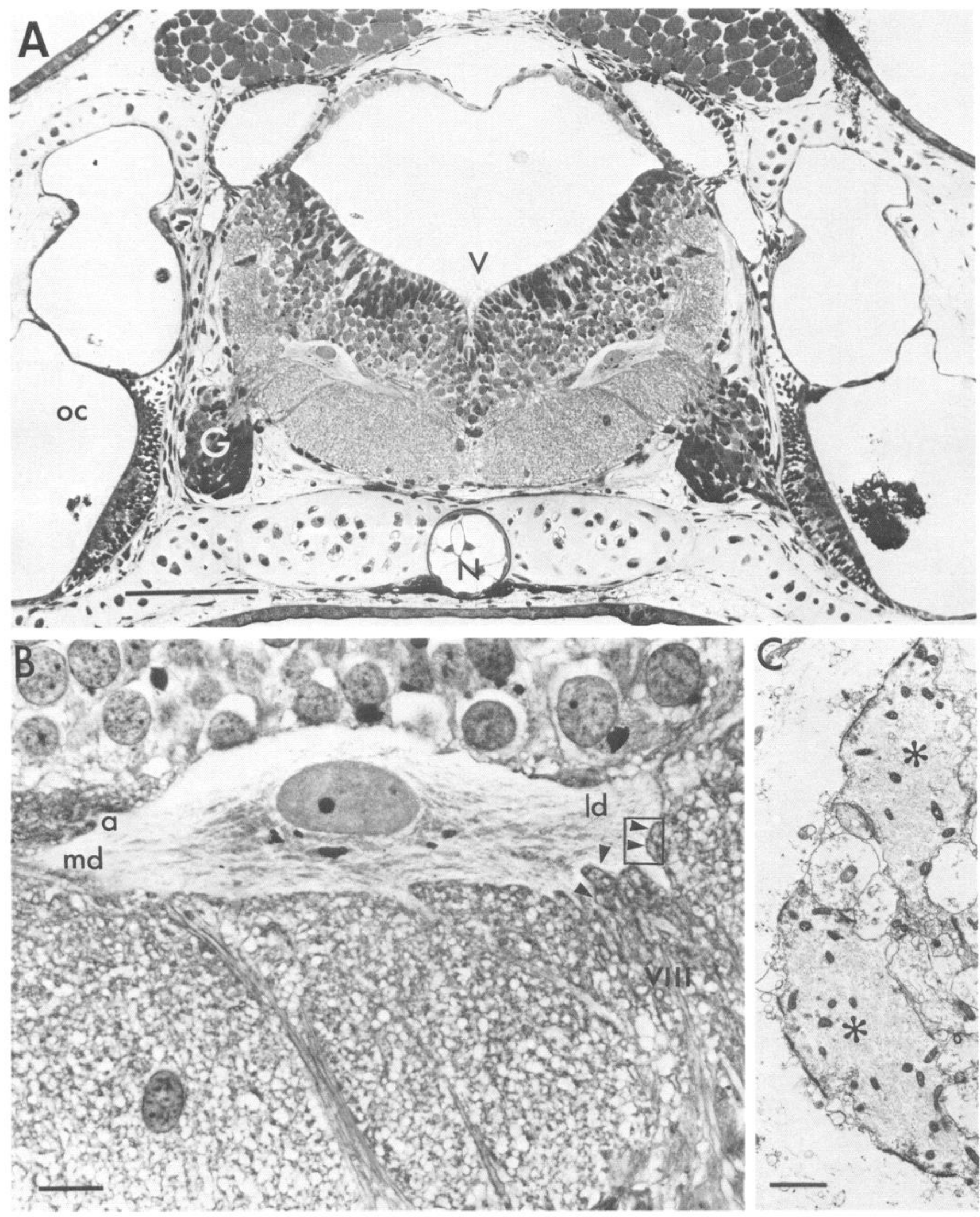

Figure 1. A, Light micrograph of an Epon-embedded, 4- $\mu$ m-thick, toluidine blue-stained cross section through the medulla of a control 21 mm larva at the level of the M-cells, nVIII ganglia $(G)$, and otic capsules $(o c)$. $V$, IVth venticle; $N$, notochord. Scale bar, $200 \mu$ m. $B$, Higher magnification of the right M-cell in $A$ showing the proximal segments of the lateral dendrite $(l d)$, medial dendrite $(m d)$, and axon $(a)$. Vestibular axons $(V I I I)$ enter the medulla at the level of the M-cell and terminate on the ventral surface and branches of the lateral dendrite as large, identifiable club endings (arrowheads) on the M-cell. Scale bar, $20 \mu \mathrm{m}$. $C$, Electron micrograph of boxed area in $B$ showing 2 club endings (*). Scale bar, $1 \mu \mathrm{m}$. 

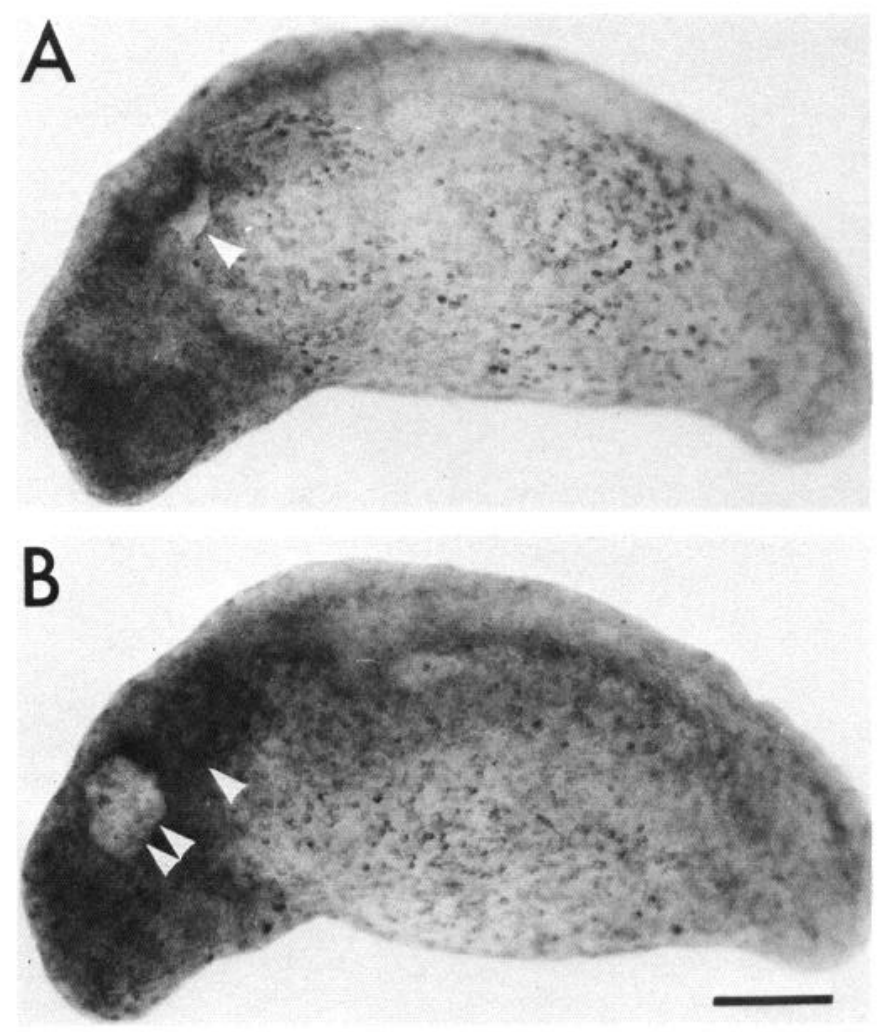

Figure 2. Stage 29 embryos $15 \mathrm{~min}$ after surgery. $A$, Donor embryo with its vestibular primordium removed (arrowhead). B. Host embryo with an extra vestibular primordium (double arrowhead) implanted rostral to the in situ one (single arrowhead). Scale bar, $0.5 \mathrm{~mm}$.

ians, Kimmel and Schabtach, 1974; Kimmel and Model, 1978). For example, a major source of afferent innervation derives from the ipsilateral vestibular nerve (nVIII). nVIII terminals in the axolotl can be identified morphologically as club endings in the light (Model, 1978) and electron microscopes (Kimmel and Schabtach, 1974; Model and Wurzelmann, 1982), and are restricted to the proximoventral surface and branches of the M-cell lateral dendrite (Fig. 1, B, C). In the developing embryo, the M-cell is first recognized at Harrison (1969) stage 34, and the earliest nVIII fibers contact the growing lateral dendrite at stage 36 (Leber, 1984). In the present study, we show enhanced localized branching of the lateral dendrite following superinnervation of the developing M-cell with afferents that have their origin in a grafted (extra) vestibular primordium. On the other hand, the dendritic branching of M-cells deprived of nVIII afferents is reduced. Preliminary reports have been published (Goodman and Model, 1985; Model and Goodman, 1986).

\section{Materials and Methods}

Microsurgery. The embryos used in these experiments were provided by the colony of axolotls maintained in our laboratory and by the one maintained at Indiana University. All operations were performed on the same side of midtailbud embryos (stages 28-30) in sterile NiuTwitty's complex salt solution ( $\mathrm{pH} 7.4-7.6$ ) with neomycin sulfate (50 $\mathrm{mg} /$ liter). After decapsulation, host embryos were prepared by unilateral removal of a small piece of ectoderm from a site immediately rostral to the in situ vestibular primordium. Donor tissue was prepared by unilateral excision of a vestibular primordium (together with its associated nVIII ganglion and overlying ectoderm). The excised vestibular primordium was then implanted in normal orientation in the site previously prepared in a host embryo (Fig. 2). Surgery was performed prior to nVIII outgrowth and M-cell differentiation. The contralateral side served as control. In 3 embryos, a patch of donor ectoderm was implanted instead of a vestibular primordium. In 6 additional embryos, the vestibular primordium was removed and then replaced in its normal position and orientation. The former group served as control for any effects of the surgical procedure used in the hosts; the latter group served as control for that used in the donors. After healing, the embryos were reared at $16^{\circ} \mathrm{C}$ in individual petri dishes through hatching to early feeding stages.

HRP-labeling and preparation for microscopy: host larvae. The ectopic nVIII in some of the experimental larvae was labeled with HRP. At the $21 \mathrm{~mm}$ stage (about 2 weeks posthatching), larvae were anesthetized with MS 222 and immobilized. Prior to adding HRP, an electrolytically sharpened tungsten needle was used to damage the vestibular sensory organs and associated peripheral nVIII fibers in the ectopic ear. A small piece of gelfoam, previously soaked in a solution containing 30\% HRP and dilute lysophosphatidylcholine, was inserted into the damaged ear capsule. The larvae recovered rapidly, and after $10-15 \mathrm{hr}$, they were reanesthetized. The heads were removed and immediately immersed in $3 \%$ glutaraldehyde, $2 \%$ paraformaldehyde, $1 \%$ acrolein, and $2.5 \%$ DMSO in $0.1 \mathrm{~m}$ cacodylate buffer $(\mathrm{pH} 7.4)$ at room temperature. After $24 \mathrm{hr}$ at $4^{\circ} \mathrm{C}$, the heads were washed several times, first in $0.1 \mathrm{~m} \mathrm{cac}-$ odylate buffer ( $\mathrm{pH} 7.4)$, and then in $0.1 \mathrm{~m}$ phosphate buffer $(\mathrm{pH} 7.4$, total time $2.5 \mathrm{hr}$ ), and each was embedded in $5 \mathrm{ml}$ of $0.5 \%$ gelatin and $30 \%$ albumin in phosphate buffer. After $2 \mathrm{hr}$, the embedding solution was hardened with $0.15 \mathrm{ml} 50 \%$ glutaraldehyde. Using a vibratome, serial cross sections, $50 \mu \mathrm{m}$ thick, were cut from the heads and suspended individually in phosphate buffer in the wells of a multiwell tissue culture dish.

All reaction solutions were prepared in $0.1 \mathrm{~m}$ phosphate buffer $(\mathrm{pH}$ 7.4). Sections were washed in 5\% cobalt chloride for $10-15 \mathrm{~min}$, rinsed in phosphate buffer, and preincubated in $0.05 \%$ 3,3'-diaminobenzidine tetrahydrochloride (DAB) for $30-40 \mathrm{~min}$. The reaction was carried out in $0.05 \% \mathrm{DAB}$ and dilute hydrogen peroxide. The extent of the reaction was determined by the accumulation of black reaction product. After 20-30 min, sections were washed in buffer, postfixed in $0.5 \% \mathrm{OsO}_{4}$ for $30 \mathrm{~min}$, washed in veronal acetate buffer ( $\mathrm{pH} 7.4)$, and en bloc stained in $4 \%$ uranyl acetate for $30 \mathrm{~min}$. Sections were dehydrated in a graded series of ethanols and flat-embedded in Epon 812. After the Epon had hardened, selected $50-\mu \mathrm{m}$-thick sections were photographed in the light microscope and then mounted onto Epon blocks. Serial sections, $4 \mu \mathrm{m}$ thick, were cut from them, mounted on glass slides, stained with toluidine blue, and photographed in the light microscope.

Control larvae and larvae with unlabeled ectopic nerves were also anesthetized at the $21 \mathrm{~mm}$ stage, and their heads were immersed in fixative as described above. All tissue washes were carried out in $0.1 \mathrm{~m}$ cacodylate buffer ( $\mathrm{pH} 7.4$, total time $1.5 \mathrm{hr}$ ). Heads were postfixed in cold $2 \% \mathrm{OsO}_{4}$ in cacodylate buffer $(2 \mathrm{hr})$, washed in veronal acetate buffer, and en bloc stained in $4 \%$ uranyl acetate $(1 \mathrm{hr})$. Heads were dehydrated in a graded series of ethanols and embedded in Epon 812. Serial cross sections, $4 \mu \mathrm{m}$ thick, were cut from the heads and photographed in the light microscope.

Microscopic analysis and $M$-cell reconstruction. The morphology of the implanted ear and nVIII ganglion was analyzed in successive 4- $\mu \mathrm{m}$ thick sections cut from unlabeled animals. The course of the ectopic $\mathrm{nVIII}$ was analyzed in successive $50-\mu \mathrm{m}$-thick sections cut from HRPlabeled animals. The morphology of M-cells was analyzed in both labeled and unlabeled larvae by comparing reconstructed experimental $\mathrm{M}$-cells with their contralateral controls. To reconstruct each M-cell, we traced its perimeter in aligned micrographs of successive sections, superimposed the traced contours, and traced the perimeter of the superimposed contours (Fig. 3). The perimeter of the superimposed contours represents a silhouette of the soma, proximal axon, major dendrites, and dendritic surface receiving nVIII terminals. Electron microscopic analysis of thin sections (see below) revealed that the dendritic branches receiving vestibular synapses had only a few higherorder dendritic branchlets that were obscure in the 4- $\mu \mathrm{m}$-thick sections. Thus, the light microscopic reconstructions represent the bulk of the dendritic surface in that region of experimental and control M-cells.

Measurement of superinnervation. The degree of superinnervation was quantified by counting vestibular synapses on experimental and control M-cells. The successive $4-\mu \mathrm{m}$-thick sections comprising each M-cell were mounted onto Epon blocks and sectioned for electron microscopy. Thin sections were collected on Formvar-coated slot grids, stained with uranyl acetate and lead citrate, and photographed in a Philips $200 \mathrm{EM}$. Club terminals were identified and counted in the montage of micrographs obtained from each thin section. One thin 


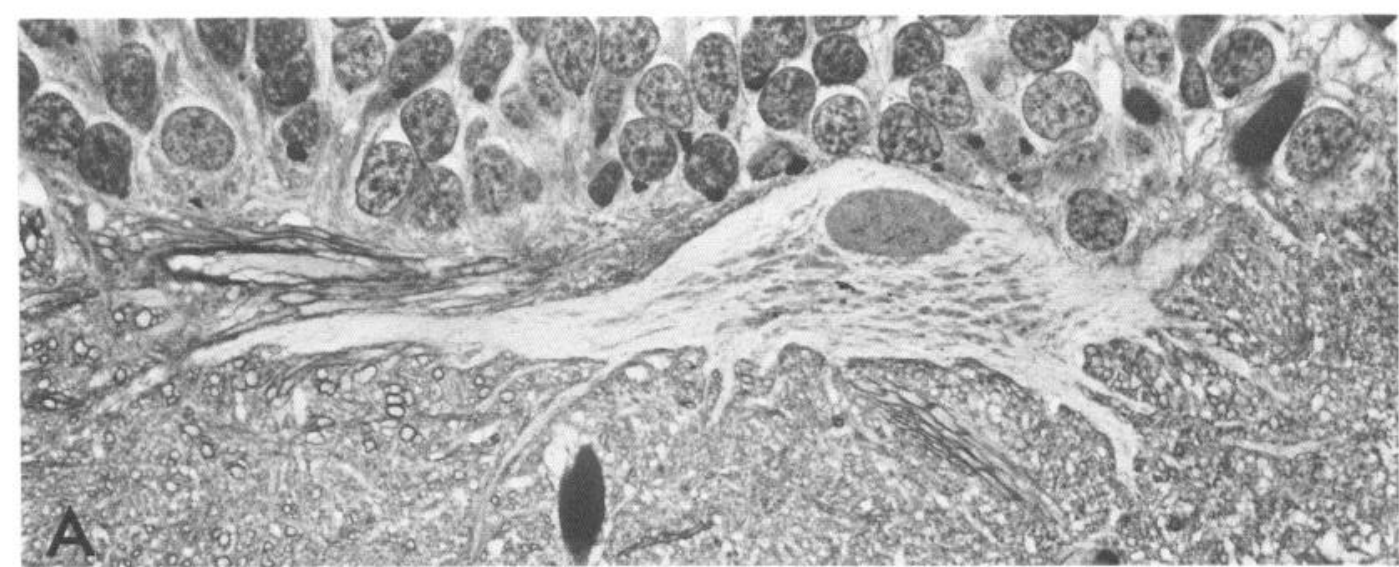

B
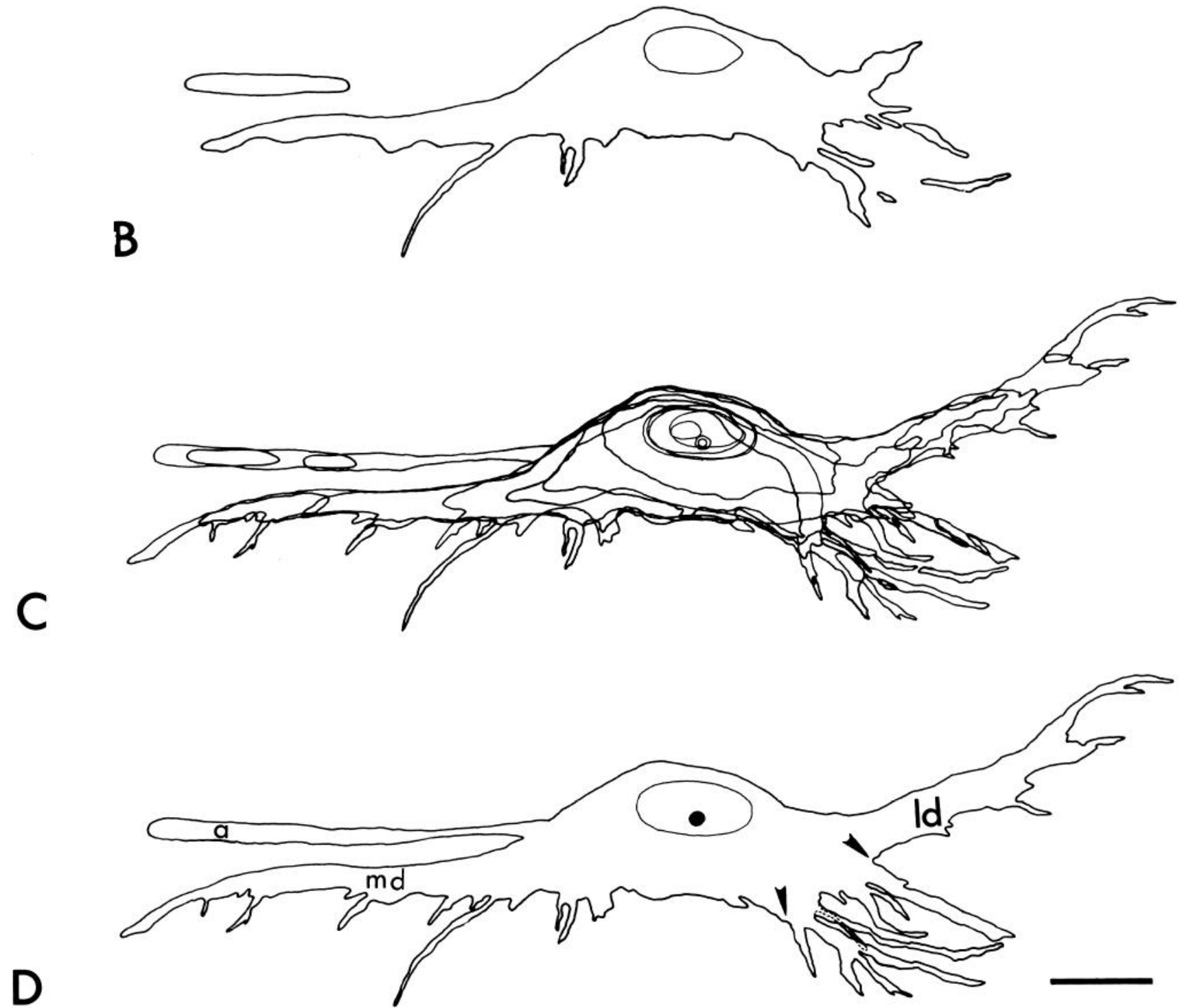

Figure 3. M-cell reconstruction. A, One of a series of light micrographs of cross sections through an M-cell. B, Perimeter of the M-cell in the section in $A$. $C$, Superimposed contours of the M-cell in the series of light micrographs. $D$, Perimeter of the superimposed contours in $C$ showing the proximoventral surface and branches of the lateral dendrite that receive nVIII terminals (between arrowheads). md, medial dendrite; ld, lateral dendrite; $a$, axon. Scale bar, $40 \mu \mathrm{m}$. 

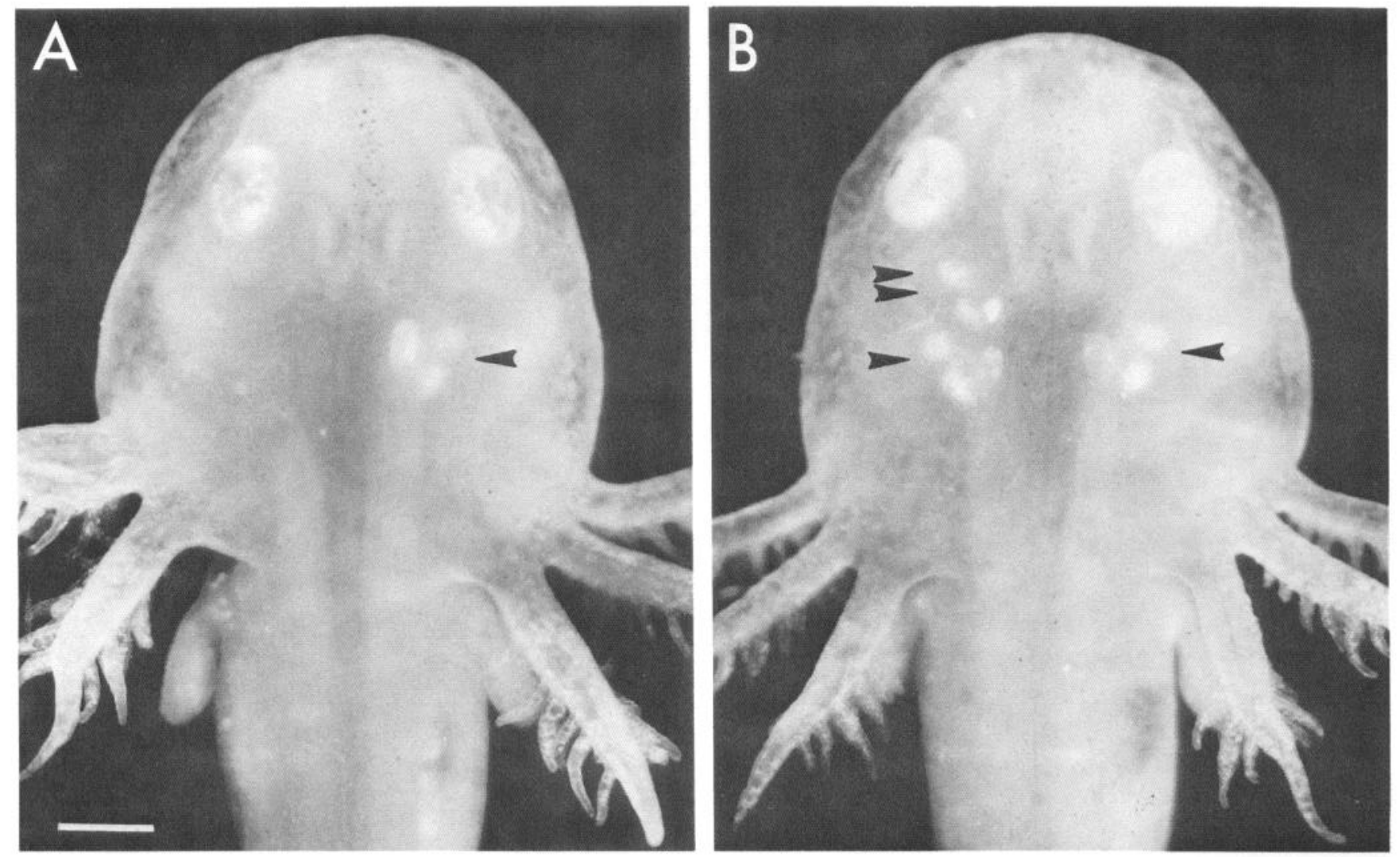

Figure 4. A, Door larva, $21 \mathrm{~mm}$. On the control side, a pair of maculae identifies the ear (arrowhead). Calcium crystals in the endolymphatic sac appear as a white opacity medial to the maculae. On the experimental side, the maculae are absent. B, Host larva, $21 \mathrm{~mm}$. On the control side, one pair of maculae identifies the ear (single arrowhead). On the experimental side, one pair of maculae identifies the in situ ear (single arrowhead) and a second pair, the implanted ear (double arrowhead). Scale bar, $1 \mathrm{~mm}$.

section from each of the successive $4-\mu \mathrm{m}$-thick sections was analyzed to determine the number of club terminals. Finally, the number of vestibular synapses on individual M-cells was calculated by adding together the number of club terminals in successive thick sections.

Preparation and analysis: donor larvae. At $21 \mathrm{~mm}$, donor larvae and their controls were anesthetized in MS 222. The heads were removed and prepared for microscopy by the procedure used for the unlabeled host larvae. The appearance of the medullae and the morphology of the M-cells were examined in successive $4-\mu \mathrm{m}$-thick sections. The branching pattern of the lateral dendrite was analyzed by comparing reconstructed experimental M-cells with their contralateral controls. nVIII tracts and M-cells were examined in the electron microscope. Selected 4- $\mu \mathrm{m}$-thick sections were re-embedded and sectioned; they contained the lateral dendrite and ventral dendritic branches of either the experimental M-cell or the contralateral control. Thin sections were photographed in a Philips 200 or 300 EM.

\section{Results}

Donor larvae

Unilateral excision of the vestibular primordium at stages 2830 deprived the ipsilateral M-cell of nVIII afferents throughout its differentiation. In the period immediately following surgery, rapid healing occurred by the movement of surrounding ectoderm into the excision site. When the larvae reached $21 \mathrm{~mm}$, the ear was identified on the control side by the white otoliths of the 2 maculae. On the experimental side, the otoliths were absent (Fig. 4A). Grossly, behavioral effects were minimal: most of the larvae remained in a symmetrical, balanced position while stationary and showed an occasional, transient roll onto the deprived side while swimming. Light microscopic examination of sections obtained from the larvae revealed that the ear, ves- tibular axons, and nVIII ganglion were absent from the experimental side (Fig. 5, $A$ and $B$ ). While nVII (special visceral sensory component) and lateral line nerve bundles were small in most of the larvae, they were intact in 2 (Fig. 5B). No disturbances of the medullae were noted, but in one larva, the long axis of the M-cell was rotated $90^{\circ}$, and in another, the M-cell was missing from the experimental side. These larvae had exaggerated abnormal swimming behavior: they made complete rotations around the rostral-caudal axis and thus appeared to spiral. These aberrations are probably the result of surgical damage. In control larvae, the excised vestibular primordia that were reimplanted developed into normal otic capsules, nVIII ganglia, and vestibular nerves.

Six pairs of reconstructed M-cells are shown in Figure 6. Five are from larvae that were deprived of a vestibular nerve $(A-E)$, and one is from a control larva in which the vestibular primordium had been reimplanted $(F)$. The M-cells deprived of vestibular input have significantly reduced dendritic branching in the region that normally receives vestibular synapses when compared to the contralateral controls (Fig. 6, $A-E$ ). There were no obvious alterations of the soma, medial dendrite, or axon. In the control larva, the dendritic branching of the M-cell in the sham-operated side looks like that of the contralateral cell (Fig. $6 F$ ). The dramatic reduction of dendritic growth by M-cells deprived of vestibular input was thus a consequence of afferent deprivation.

Electron microscopic analysis of sections containing analagous portions of the lateral dendrite from experimental and 


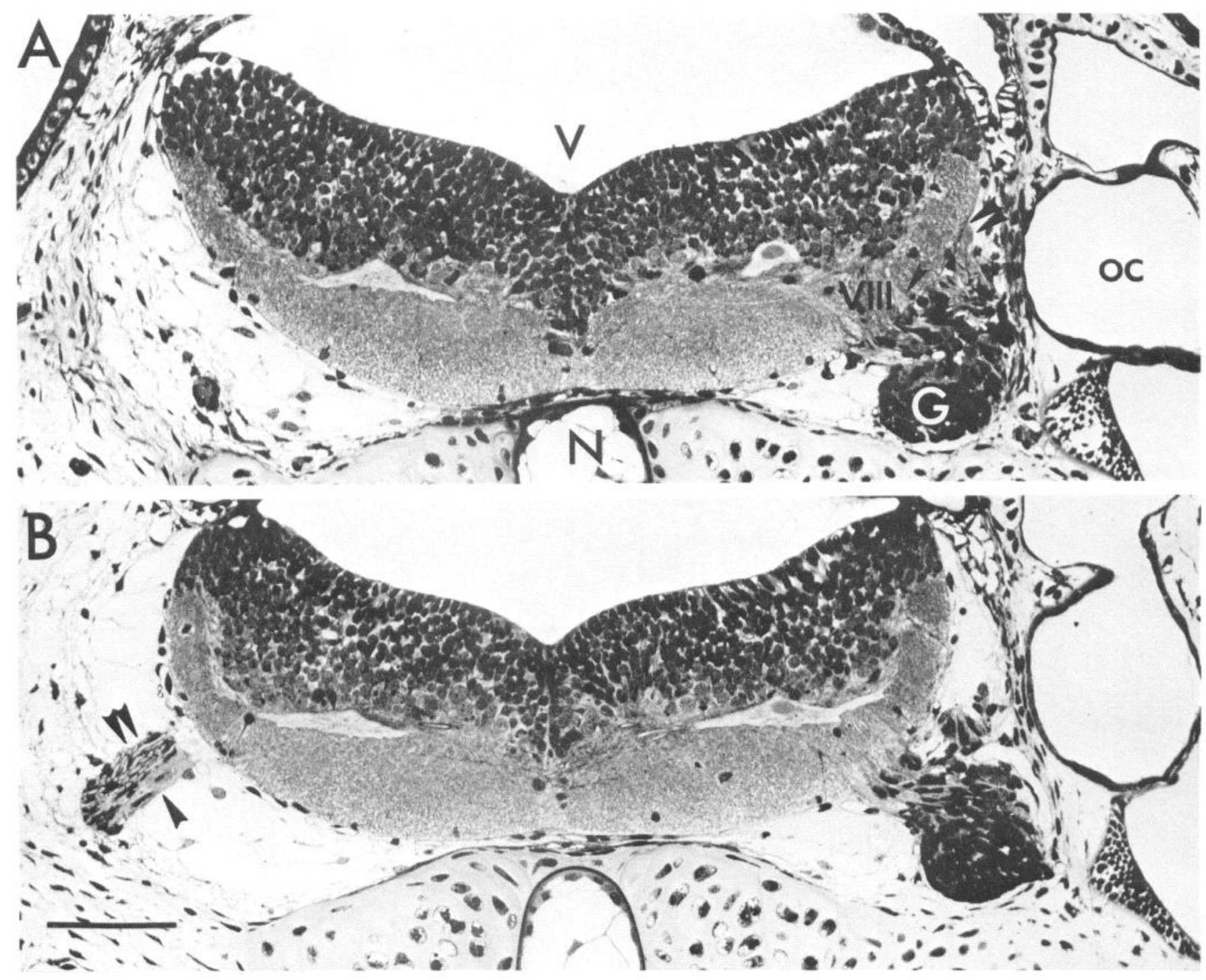

Figure 5. Light micrographs of cross sections through the medullae of two $21 \mathrm{~mm}$ donor larvae at M-cell level. $A$, The otic capsule (oc), nVIII ganglion $(G)$, and vestibular axons $(V I I I)$ are present on the control side and absent on the experimental side. A root of the lateral line nerve (double arrowhead) and the visceral sensory component of nVII (single arrowhead) enter the medulla near nVIII on the control side. On the experimental side, reduced lateral line nerve roots enter the medulla in more rostral sections, and a small visceral sensory component of nVII enters in more caudal sections. $V$, IVth ventricle; $N$, notochord. $B$, Intact lateral line nerve bundle (large axons, double arrowhead) and sensory component of nVII (small axons, single arrowhead) are present on the experimental side. Scale bar, $200 \mu \mathrm{m}$.

control M-cells revealed normal vestibular axons and terminals in the control side and neither in the experimental side (Fig. 7). The terminals present on the appropriate dendritic surface of deprived M-cells look like the nonvestibular terminals on the corresponding region of controls.

\section{Host larvae}

Superinnervation of the M-cell was brought about by the unilateral implantation of an extra vestibular primordium (together with its associated nVIII ganglion) rostral to the in situ one in midtailbud embryos. Ninety-three embryos received an extra vestibular primordium; 72 survived to reach $21 \mathrm{~mm}$ in length. On the experimental side of 51 of the larvae, the ectopic and in situ ears looked normal in the dissecting microscope (Fig. $4 B$ ). The ectopic nerves in 33 of these larvae were labeled with HRP; the ectopic nerves in the remaining 18 were not. Light microscopic examination of sections obtained from larvae with unlabeled ectopic nerves (and thus with intact extra ears) revealed that most of the grafted vestibular primordia developed into anatomically normal ears (as in Fig. $8 \mathrm{~A}$ ). The passage of ectopic axons through the medulla was traced in larvae with labeled axons: the fibers entered the nVIII tract at the level of $\mathrm{nV}$ (Fig. 8, $A$ and $B$ ), and they remained confined to the appropriate tract as they coursed caudad toward the ipsilateral M-cell (Fig. 8C). Once there, profiles of labeled axons were clustered near the appropriate region of the M-cell lateral dendrite (Fig. 9A). In addition, unlabeled nVIII axons from the in situ vestibular ganglion entered the nVIII tract at the normal entry site at the level of the M-cell and coursed toward the same region (Fig. 9A). Electron microscopic examination of experimental M-cells revealed that labeled vestibular terminals were distributed among unlabeled ones on the proximoventral surface and branches of the cell's lateral dendrite (Fig. 9B). Thus, in larvae that developed with an extra vestibular primordium, 

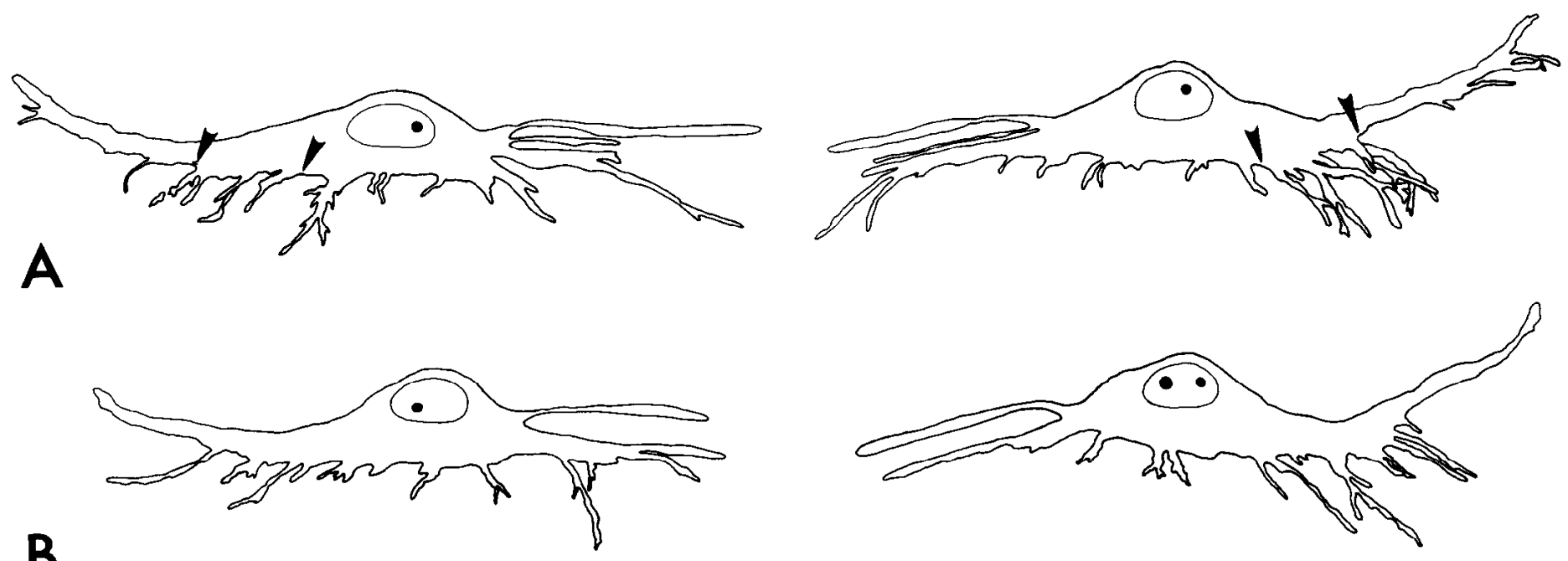

B

A
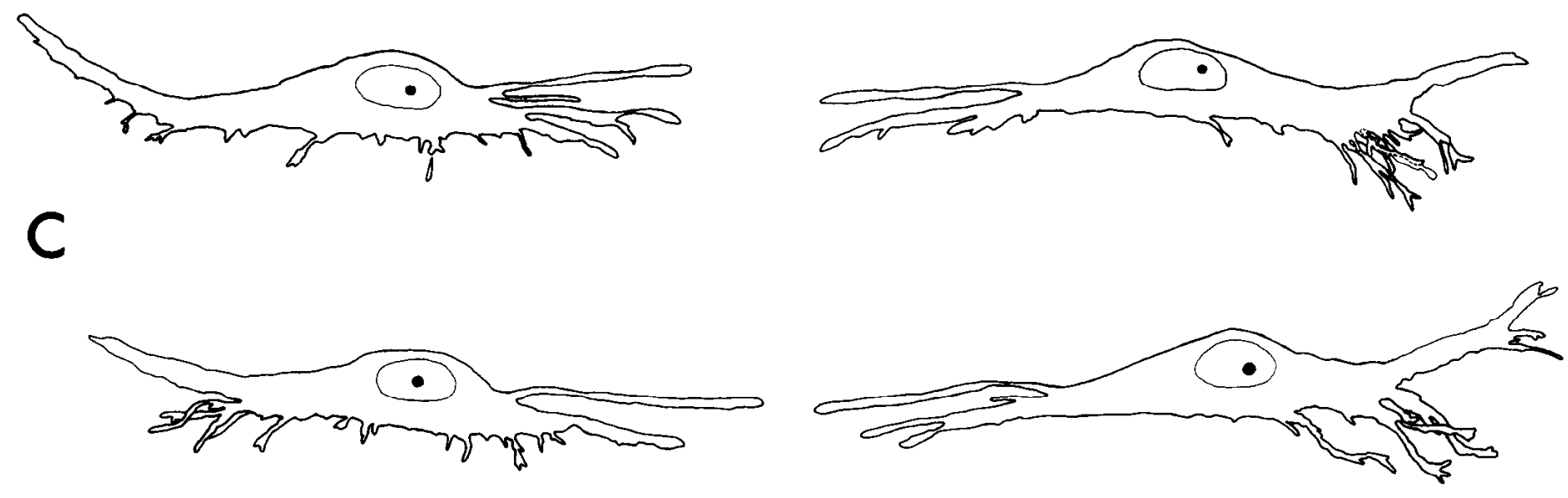

D
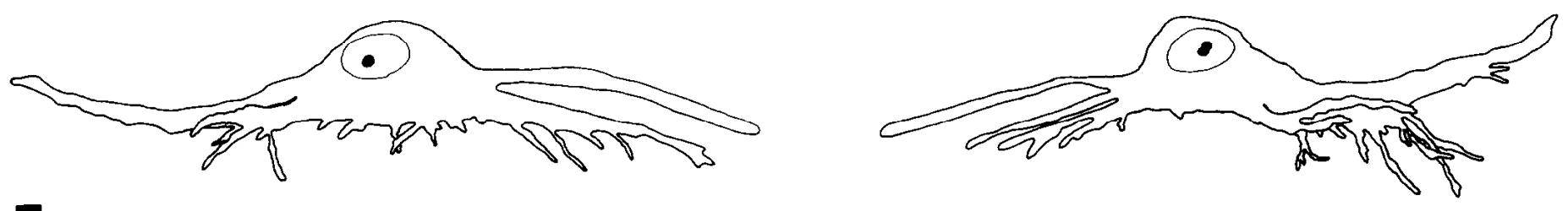

$E$
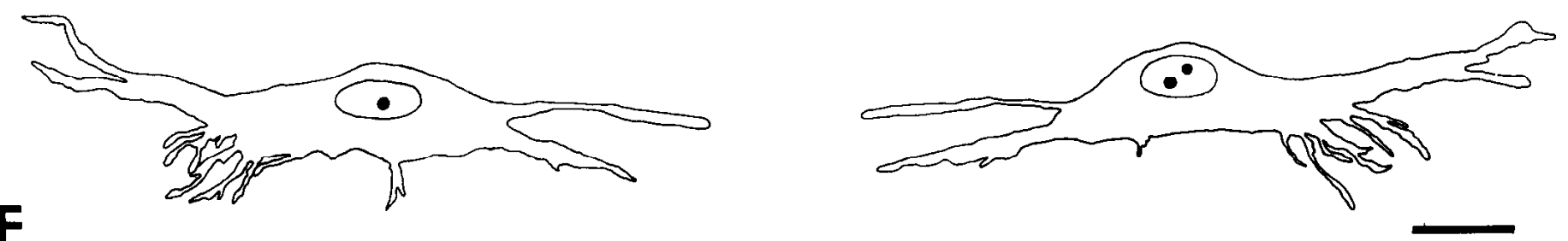

Figure 6. Contours of reconstructed pairs of M-cells. Each experimental cell (left) is paired with its control (right). The proximoventral surface of the lateral dendrite of each experimental cell (between arrowheads) is compared with that of its contralateral control. $A-E$. There is a dramatic reduction of dendritic surface on the deprived M-cells. $F$, M-cells are equally branched when the excised vestibular primordium is reimplanted. Scale bar, $50 \mu \mathrm{m}$.

axons from both the in situ and ectopic vestibular ganglia made synaptic contact on the appropriate region of the ipsilateral M-cell.

The effect of superinnervation on the morphogenesis of the
M-cell was evaluated by comparing reconstructed experimental $\mathrm{M}$-cells with the contralateral control cells. Fifteen of the 18 pairs of M-cells from animals with unlabeled ectopic nerves were reconstructed. M-cells from the remaining 3 larvae were 

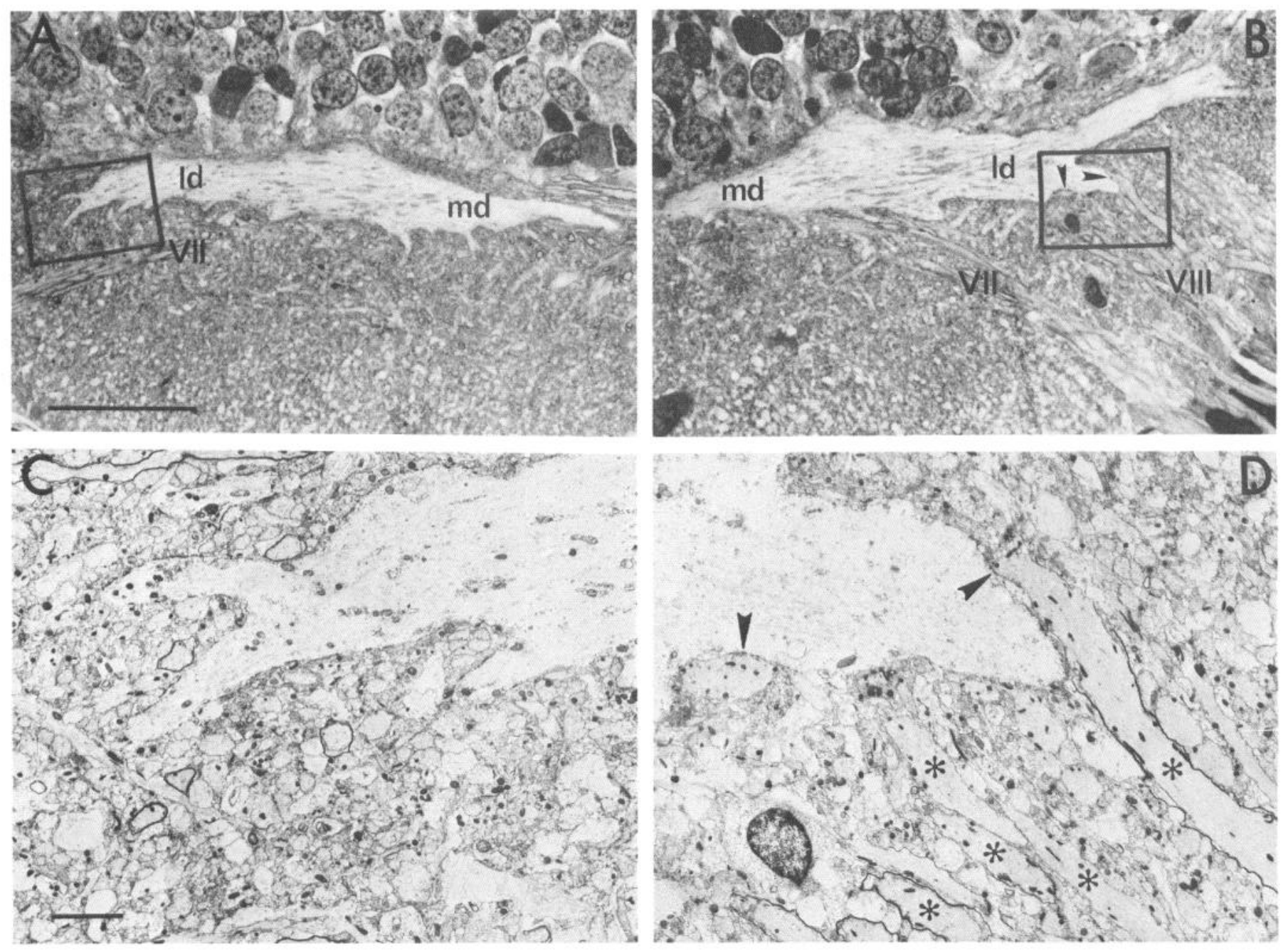

Figure 7. $A$ and $B$, Light micrographs of sections through the caudal portion of the experimental M-cell $(A)$ and the control M-cell $(B)$ derived from the same donor larva. Contours of the reconstructed cells from this animal are shown in Figure $6 D$. $l d$, lateral dendrite; $m d$, medial dendrite; $V I I$, motor component of nVII. Large nVIII axons (VIII) and club endings (arrowheads) are present in $B$ but absent in $A$. Scale bar, $50 \mu \mathrm{m}$. $C$ and $D$, Electron micrographs of the boxed areas in $A$ and $B$, respectively. Vestibular axons (*) and terminals (arrowheads) are present in $D$ only. Scale bar, $5 \mu \mathrm{m}$.

not reconstructed because of poor preservation, lost sections, or morphologically anomalous M-cells in both sides of the medulla. Of the 33 larvae with labeled ectopic nerves, 6 pairs of $\mathrm{M}$-cells were reconstructed. The selected larvae had maximally labeled ectopic nerves and well-preserved M-cells. In all, 21 experimental larvae were analyzed. Figure 10 shows 6 pairs of reconstructed $\mathrm{M}$-cells from larvae that had developed with grafted vestibular primordia, and one pair from a control animal that had developed with a grafted patch of ectoderm. The dendritic branching pattern in the region receiving vestibular synapses is greatly enhanced on experimental M-cells compared with the corresponding contralateral control cells (Fig. 10, A$D$ ). The experimental M-cells exhibited a range of increase in dendritic surface: eleven showed an exuberant increase (e.g., Fig. 10, $A-D$ ), 6 showed a moderate increase (e.g., Fig. 10E), and 4 approximated the contralateral controls (e.g., Fig. 10F). There was no case in which the control cell was more highly branched than the experimental cell. No changes were observed in the size and shape of the M-cell soma, medial dendrite, or axon. The reconstructed pair of M-cells from a control larva with a grafted patch of ectoderm shows that the dendritic branching pattern of the M-cell in the operated side looks like the branching pattern of the contralateral control (Fig. 10G). Light microscopic re-examination of unlabeled animals (those with intact extra ears) showed that 3 of the experimental M-cells with no increase in dendritic branching and one with a moderate increase came from animals in which the grafted ears were somewhat malformed and the nVIII ganglia were small. These abnormalities may account for the fact that little or no extra dendritic growth was observed. A unique dendritic branching pattern was found on one of the superinnervated M-cells (not shown). A very large dendritic branch originated from the proximocaudal surface of the medial dendrite. It coursed $60 \mu \mathrm{m}$ caudolaterally, entered the nVIII tract, coursed an additional $35 \mu \mathrm{m}$ within the tract, and then terminated. Further examination in the EM revealed that the segment in the nVIII tract received many vestibular contacts. Taken together, the reconstructions show that nVIII superinnervation of the M-cell produces a significant localized increase in postsynaptic dendritic surface.

The extent of superinnervation was determined by counting and comparing vestibular synapses on experimental and control 


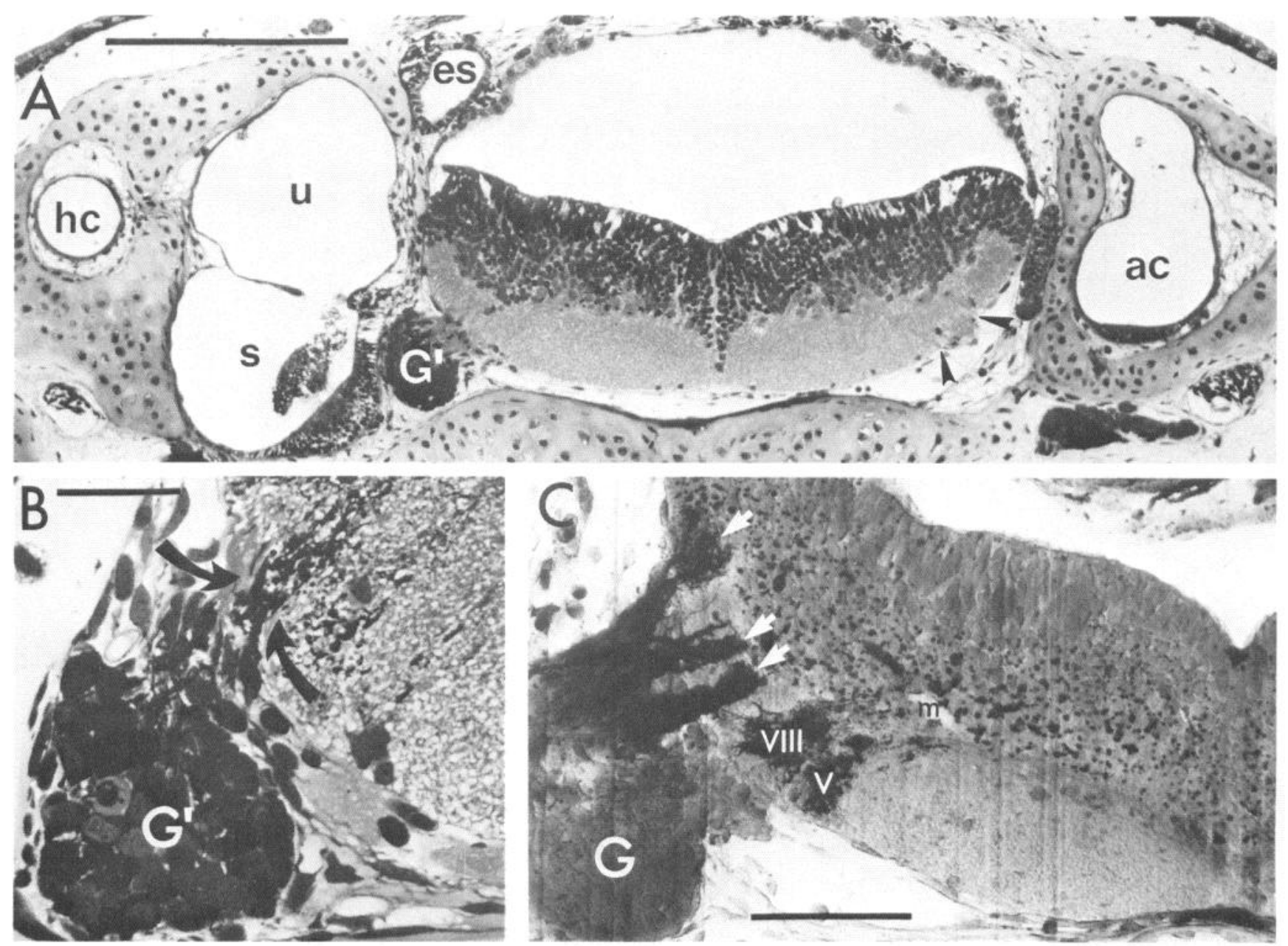

Figure 8. A, Cross section through the rostral medulla of a $21 \mathrm{~mm}$ host larva showing the anterior semicircular canal $(a c)$ and entry of nV $($ between arrowheads) into the medulla on the control side, and the middle of the implanted ear on the experimental side. $u$, utricle; $s$, sacculus; $h c$, horizontal semicircular canal; es, endolymphatic sac; $G^{\prime}$, nVIII ganglion. The implanted ear at the level of nV looks like the control ear at the level of the M-cells. Scale bar, $500 \mu \mathrm{m}$. B. Ectopic nVIII and ganglion labeled with HRP. Labeled neurons are present in the ganglion $\left(G^{\prime}\right)$ and labeled axons enter the medulla (between arrows). Scale bar, $50 \mu \mathrm{m}$. $C$, Vibratome cross section, $50 \mu \mathrm{m}$ thick, at the level of the M-cell $(\mathrm{m})$. Neurons in the in situ nVIII ganglion $(G)$ are not labeled; the labeled axons in the nVIII tract $(V I I I)$ originate in the ectopic nVIII ganglion. nV (V) and lateral line nerve bundles (arrows) are also labeled. Scale bar, $150 \mu \mathrm{m}$.

M-cells. Club terminals were easily identified because they are very large (3-12 $\mu \mathrm{m}$ in diameter; Model and Wurzelmann, 1982), make morphologically mixed (chemical and electrical) synaptic contacts (Model and Wurzelmann, 1982), have mitochondria

Table 1. Total number of vestibular synapses found on control and experimental M-cells

\begin{tabular}{|c|c|c|c|}
\hline \multirow[b]{2}{*}{ Animal } & \multicolumn{2}{|c|}{ Number of vestibular synapses } & \multirow{2}{*}{$\begin{array}{l}\text { Increase } \\
(\%)\end{array}$} \\
\hline & Control & Experimental & \\
\hline 1 & 127 & 212 & 67 \\
\hline 2 & 124 & 165 & 33 \\
\hline 3 & 115 & 163 & 42 \\
\hline 4 & 115 & 150 & 30 \\
\hline Mean & 120 & $173^{a}$ & 43 \\
\hline
\end{tabular}

The results for 4 host larvae are shown; reconstructions of the M-cells in animals $1-3$ are presented in Figure 10, $A-C$, respectively.

${ }^{a}$ Significantly greater than control $(p<0.02$, paired-sample $t$ test). grouped near the contact region, and contain densely packed, highly organized neurofilaments. Club terminals were included in the data, however, only if the electron micrographs revealed identifiable chemical or gap junctions with the M-cell (Fig. 11). While this restriction may have led us to underestimate the total number of terminals present (i.e., there may not be a synaptic specialization in the selected thin section), it minimized the risk of counting a single nVIII terminal more than once. The same criteria were used to analyze both the control and experimental sides. Thus, our analysis provided a valid index for comparing the quantity of nVIII afferents in contact with each M-cell. Vestibular synapses were counted on the experimental and control sides of 4 animals (Table 1). The mean number of vestibular synapses on experimental M-cells was significantly greater than that on control cells $(p<0.02$, paired-sample $t$ test). No apparent change in the frequency of synapses per unit surface was observed. A contour map that shows the distribution of nVIII synapses on the experimental M-cell in animal 4 (Table 1 ) is shown in Figure 12. The ectopic nerve in this animal was labeled with HRP. 

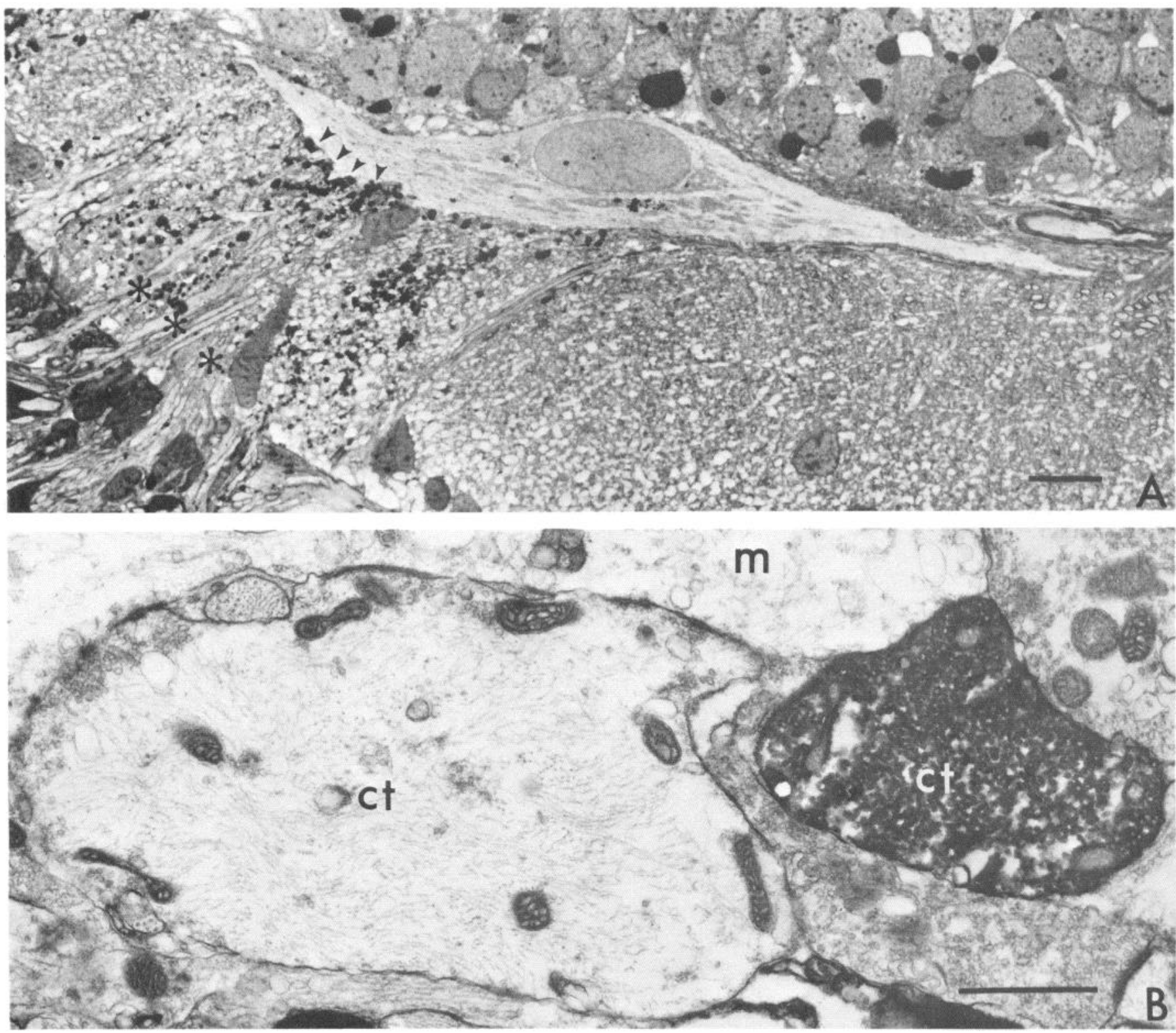

Figure 9. A, Cross section through an M-cell showing labeled axons of ectopic origin (black dots near arrowheads) clustered near the proximoventral surface of the lateral dendrite in the experimental side. Entry site of unlabeled axons from the in situ nVIII ganglion as they course toward the same region (*). Scale bar, $20 \mu \mathrm{m}$. $B$, Labeled and unlabeled club terminals $(c t)$ in synaptic contact with the M-cell $(m)$. Scale bar, $1 \mu \mathrm{m}$.

\section{Discussion}

\section{Deprivation}

When the M-cell is deprived of vestibular afferents at early embryonic stages, elaboration of the dendritic branches that normally receive nVIII terminals is greatly reduced. The excision of the otic vesicle was performed unilaterally in midtailbud embryos. The absence of the otic capsule and vestibular ganglion in the larvae confirmed that the excised tissue contained the vestibular primordium and nVIII ganglion cell precursors. That the appropriate region of the M-cell ipsilateral to the surgery was devoid of club terminals shows that no interaction between ingrowing vestibular afferents and postsynaptic dendritic surface occurred during M-cell differentiation. The localized reduction of dendritic surface on the deprived lateral dendrite indicates that the formation of afferent contacts is essential to the normal development of the dendritic branching pattern. Proof that the deficient branching was the consequence of afferent deprivation and not surgical damage lies in the morphology of the reconstructed M-cells from sham-operated larvae: the dendritic branching on the M-cell in the operated side was as extensive as that in the contralateral side.

Studies have shown that some target neurons depend on specific sources of afferent innervation for their survival. In her classic experiment, Levi-Montalcini (1949) observed that the removal of the otocyst from developing chick embryos produced an arrest of differentiation, regressive changes, and the disappearance of neurons in the central cochlear nuclei. The results of a similar study in the same system confirmed that some of the neurons in the deprived cochlear nuclei degenerate (Parks, 1979). Early studies by Piatt $(1947,1969)$ examined whether M-cell differentiation or maintenance depends on $\mathrm{nVIII}$ input. 

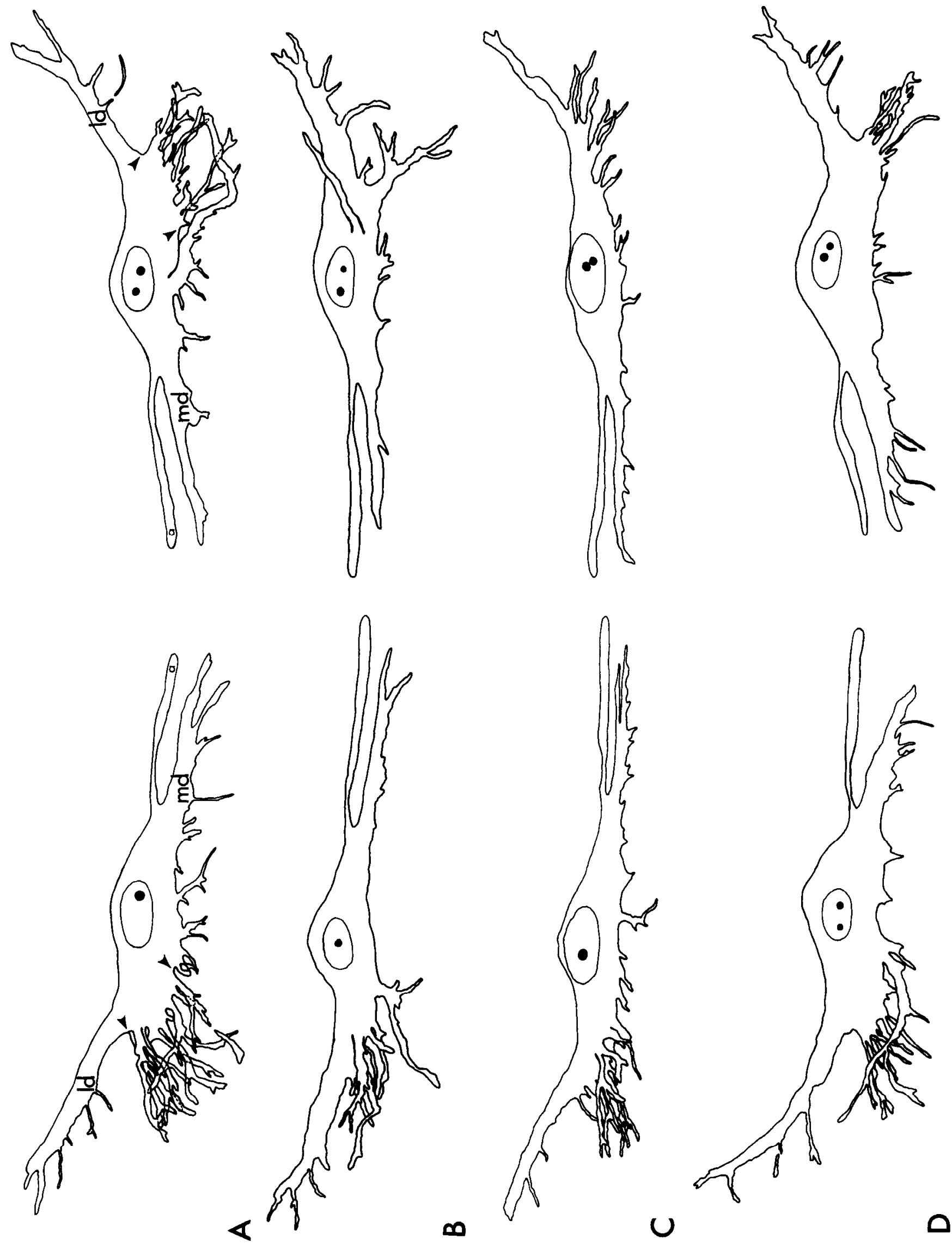


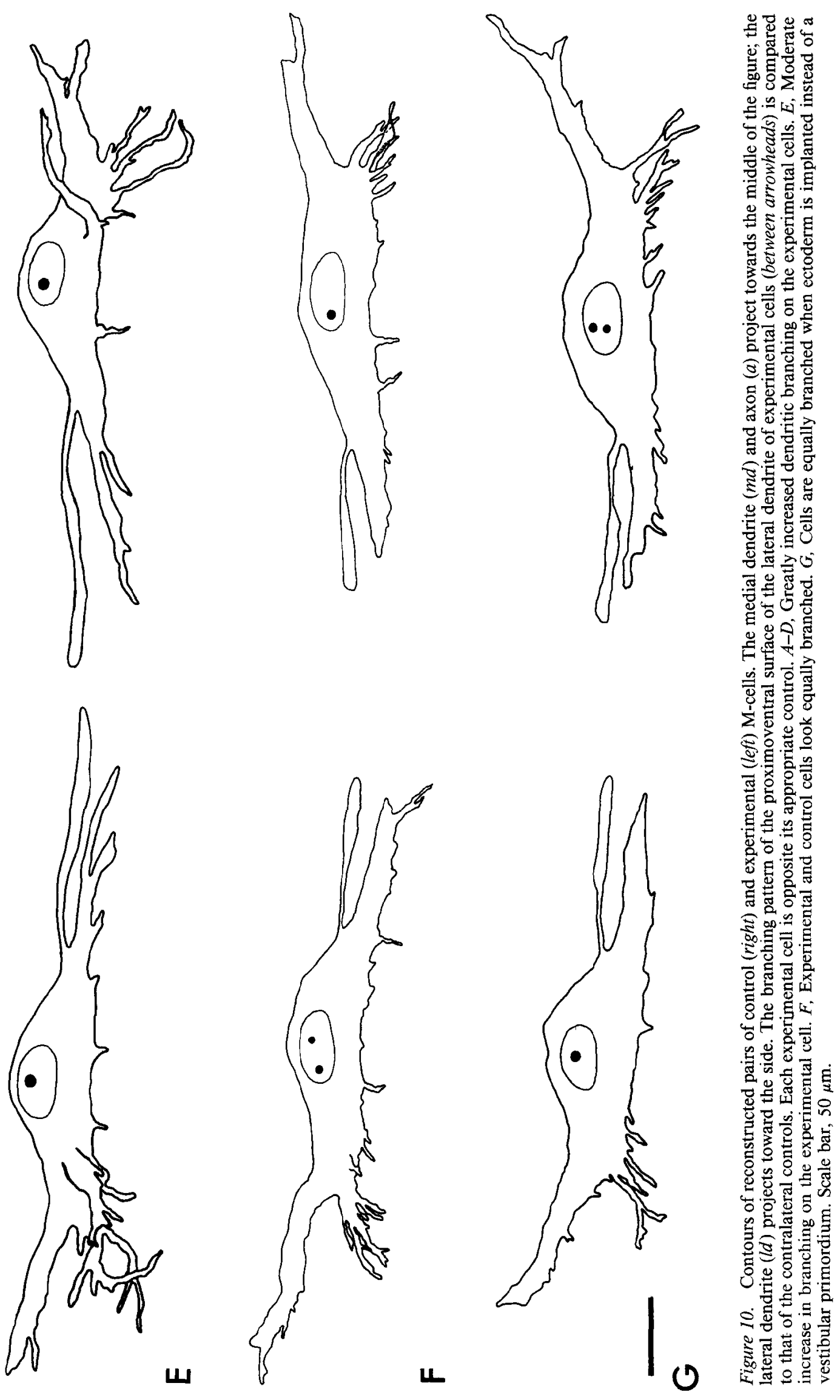




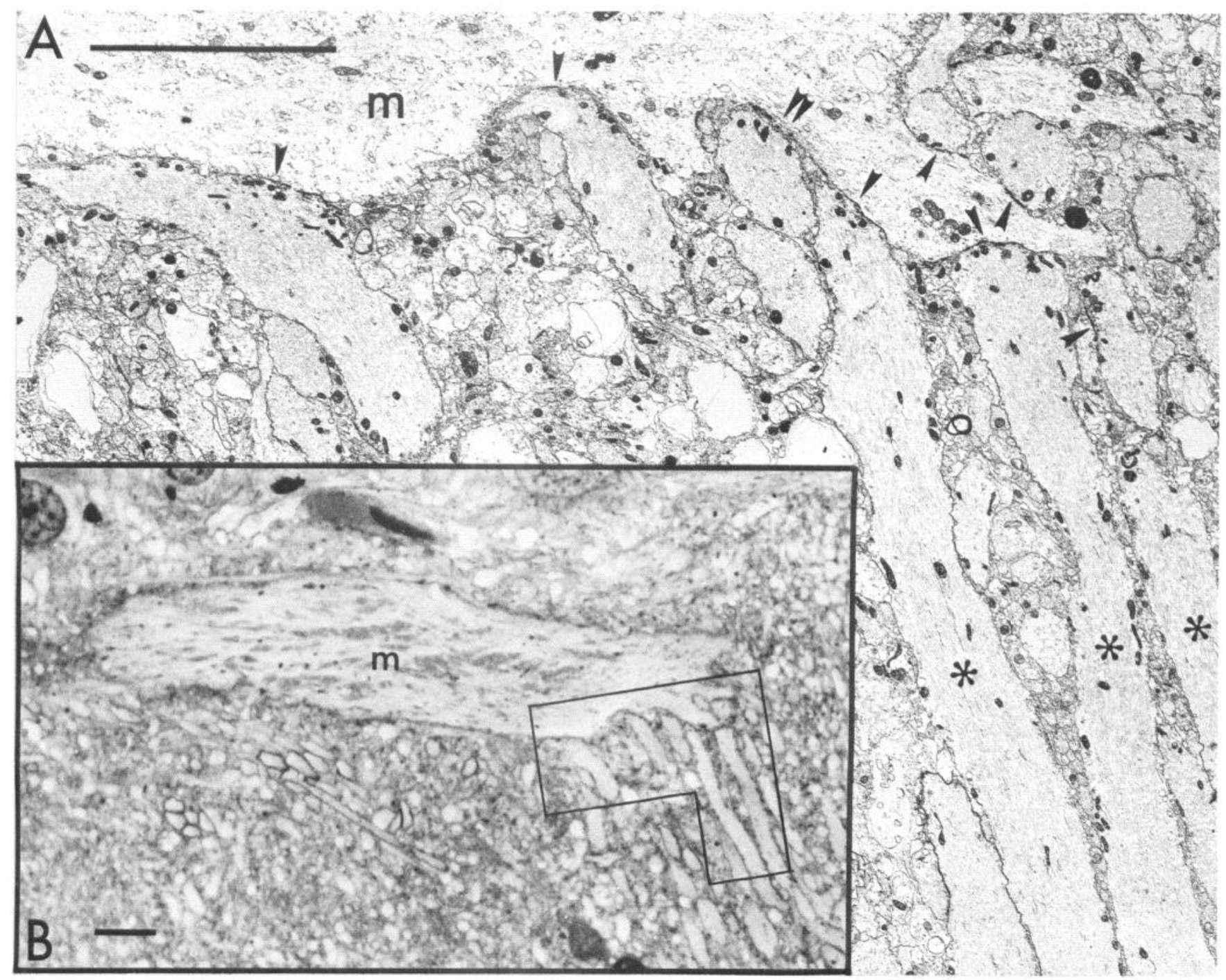

Figure 11. A, Electron micrograph of the region of vestibular contacts on the M-cell shown in the light micrograph, $B . m$, M-cell; *, vestibular axons. Club endings forming synaptic contact with the M-cell were counted (single arrowheads); terminals without a visible synapse were not (e.g., double arrowheads). Scale bars, $10 \mu \mathrm{m}$.

After removing the otic vesicle from a large number of Ambystoma embryos at stage 27, Piatt (1969) observed that the M-cell was missing from the operated side in about one-third of the animals and concluded that $\mathrm{M}$-cell differentiation depends on the presence of nVIII. In a more recent study, however, the $\mathrm{M}$-cell was consistently present in the experimental side after removal of the otic vesicle at late tailbud stage 34 (Kimmel et al., 1977). Kimmel suggested that when the cell is deprived early, it may fail to appear. The embryos used in our study were at stages similar to those used by Piatt. We found only one larvae in which the M-cell was absent and another in which the cell was rotated; we attribute these results to surgical perturbations. In all of the other larvae, the experimental M-cells were present and properly oriented. These results are consistent with the interpretation that $\mathrm{M}$-cell differentiation does not depend on the presence of nVIII. In addition, our results disagree with Piatt's (1969) observation that, when present, the experimental M-cells are normal in their appearance and extent. In the present report, the reconstructions show that the deprived dendritic branches are significantly altered.
In the axolotl, Kimmel et al. (1977) observed a decrease in the dendritic branching pattern and in the diameter of the proximal lateral dendrite of M-cells that were deprived of vestibular input. In the present work, surgery was performed at earlier stages (28-30 vs 34), reducing the chance that some of the axons had already grown to and contacted the dendrite. Furthermore, the larvae were analyzed at a later stage $(21 \mathrm{~mm}$ or about $14 \mathrm{~d}$ posthatching versus embryonic stage 45 ). Despite these differences, the data are consistent and show that normal growth of dendritic branches on the proximal lateral dendrite depends on the formation of nVIII synapses there.

\section{Superinnervation}

When a developing M-cell is innervated by extra vestibular fibers, there is an increase in its dendritic surface that is restricted to the superinnervated region. The extra axons originate in an ectopic vestibular ganglion that developed from a grafted vestibular primordium; the graft was performed unilaterally in midtailbud axolotl embryos. The structures that developed from the graft were normal insofar as the gross appearance and the mi- 


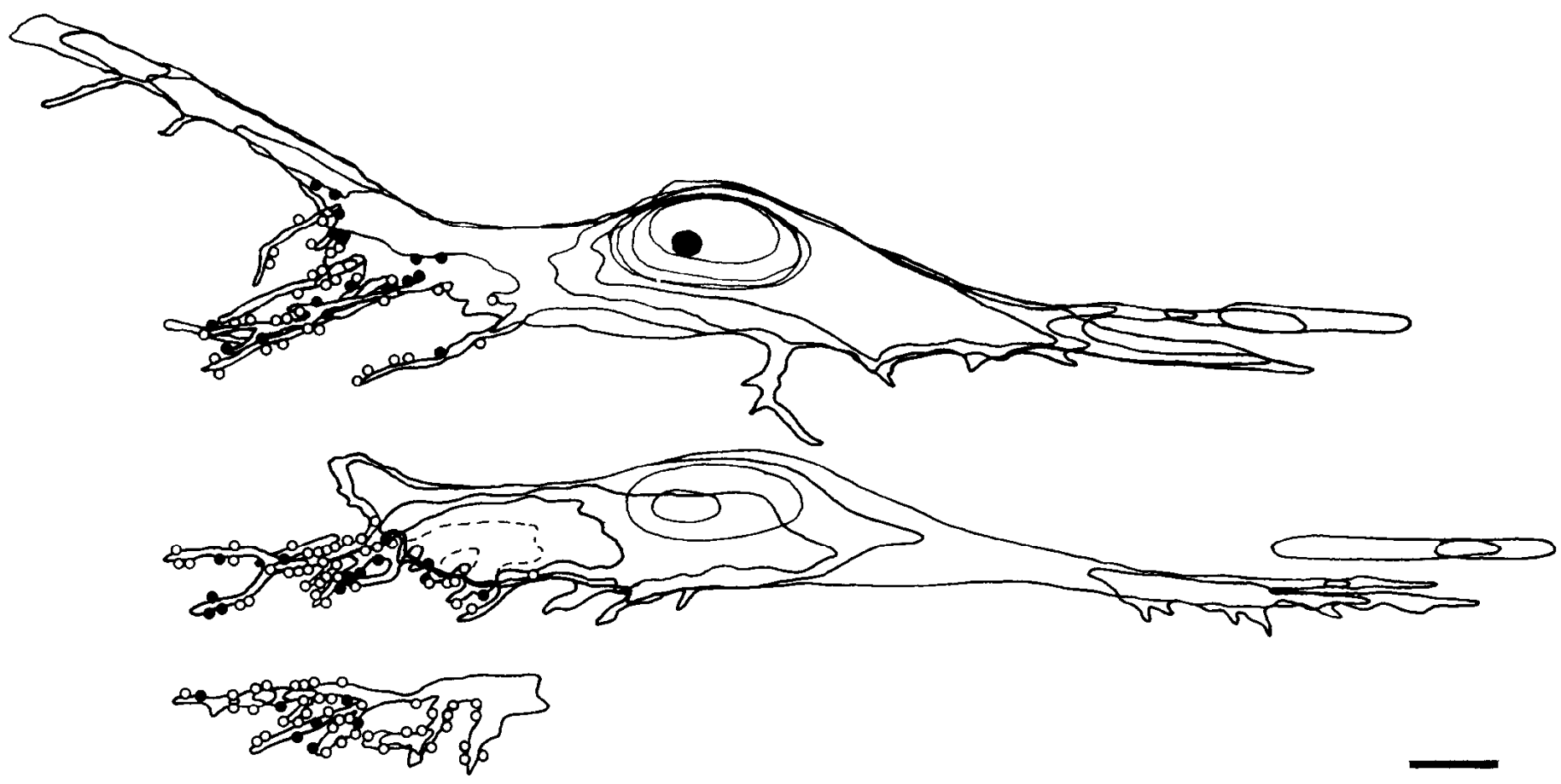

Figure 12. Distribution of HRP-labeled (black dots) and unlabeled (white dots) vestibular synapses on the superimposed contours of a superinnervated $\mathrm{M}$-cell (the same cell is shown in Fig. $10 \mathrm{C}$ ). The rostral contours are at the top, the middle contours in the middle, and the caudal contours below. The caudal segment fits onto the middle segment along the dashed lines. Scale bar, $20 \mu \mathrm{m}$.

croscopic anatomy of the utricle, sacculus, and semicircular canals were like those of $i n$ situ ears. The passage of ectopic nVIII fibers to the region of the M-ccll latcral dendritc that also received in situ nVIII terminals, and the formation of club endings there, show that the extra nVIII axons terminated on the appropriate region of the target. Proof that this region was in fact superinnervated lies in the comparison of the number of vestibular terminals on experimental $\mathrm{M}$-cells versus that on the contralateral controls: a significantly greater number was found on experimental M-cells. That superinnervation results in localized enhancement of dendritic branching on the lateral dendrite indicates that the formation of afferent contacts stimulates dendritic growth.

In a study of the growth and branching of the M-cell, Jacoby and Kimmel (1982) observed that the density of forming synapses is greatest on rapidly expanding regions of the cell. This observation supports the hypothesis that interactions between afferent fibers and developing dendrites influence dendritic branching patterns, and the authors suggested that the forming synapses stimulate dendritic growth. By introducing supernumerary afferents, we were able to look at the transsynaptic effects of ingrowing axons on the postsynaptic target more directly: the enhanced dendritic branching pattern elaborated by superinnervated $\mathrm{M}$-cells indicates that the interaction is one in which ingrowing axons induce dendritic growth. Furthermore, the present results show that extra afferents are capable of stimulating a target neuron to increase its dendritic surface to an extent greater than that found on controls.

There are a number of contradictory observations in the literature regarding the presence and effect of superinnervation. The tectum is innervated by an excess of optic axons in 3-eyed frogs (Constantine-Paton and Law, 1978) and in fish when the retinal projection is compressed onto a half tectum (Gaze and Sharma, 1970). Some tectal neurons have an altered dendritic orientation in tecta receiving afferents from an extra retina (Katz and Constantine-Paton, 1985), but an increase in dendritic branching was not reported. Although extra optic axons innervate the tectum, there remains the question of whether an increase in number of synaptic terminals occurs. This question has been approached in studies of half-tecta that receive compressed retinal projections. After ablating the caudal half-tectum in adult goldfish, Murray et al. (1982) found no increase in the density of synaptic terminals or evidence of dendritic hypertrophy within the remnant half-tectum. The authors suggest that the absence of an increased synaptic terminal density implies that each optic axon in the compressed projection made fewer synaptic contacts, and that superinnervation was therefore not a consequence. In a similar study, an increase in optic terminal density was reported (Marotte, 1981), but the extent of the dendritic arbors on tectal neurons was not examined. In our system, where the postsynaptic target is a single identified neuron, we were able to count afferent terminals as a measure of superinnervation, and then examine, through reconstructions of the target cell, the dendritic branching pattern for altered morphology.

Dendritic sprouting has been observed on invertebrate interneurons. In Daphnia, Macagno (1977) found displaced branches on optic ganglion cells in areas where there were extra presynaptic fibers. Studies of uniquely identified neurons in other insects have shown that while removal of a source of afferent innervation reduced dendritic branching at the sites of deprivation, the reduction coincided with expansion of dendritic surface in regions receiving functional afferents (in grasshoppers, Shankland et al., 1982; in crickets, Hoy et al., 1985). This observation suggests that dendritic growth is regulated by competition for a limited supply of a cellular component (Shankland et al., 1982). Whether the dendritic surface area of the M-cell is circumscribed by a restrictcd quantity of a cellular component 
is not clear: the overproduction of dendritic branches in the superinnervated region did not appear to occur at the expense of growth elsewhere, but the M-cell reconstructions may obscure a reduction in fine higher-order branches that could be present on parts of the medial and distal lateral dendrites not examined in the EM. In a related study, Murphey et al. (1983) showed that the afferent projections of supernumerary cercal sensory neurons are functional and occur in their proper target areas, but the authors did not indicate whether the postsynaptic neurons produced extra dendritic surface and, if so, whether excess growth coincides with diminished growth elsewhere.

The mechanism by which afferents induce dendritic growth is unknown. Synaptic activity, diffusable factors, and direct terminal contact are possible mediators. The results of a variety of experiments lend support to the hypothesis that neural activity is important in stimulating dendritic growth, but they do not rule out a contributing effect of afferent contact. For example, the basal dendritic branches on cortical pyramidal cells are more complex in rats subjected to increased sensory input and motor activity (Holloway, 1966; Volkmar and Greenough, 1972). In multineuronal systems in which specific functions and inputs are not well defined, morphological changes are difficult to interpret as a direct result of increased afferent activity. In developing chicks, observations regarding the role of afferent activity in the differentiation of the nucleus laminaris are contradictory: whereas afferent activity has been implicated in the regulation of the spatial gradient of dendritic size (Smith, 1981), this size gradient is not changed when the otocyst, and thus afferent activity, is removed although the dendritic arbors are reduced overall (Parks, 1981). In crickets with a single gene mutation, $f l$, a reduccd dendritic arborization was found on the medial giant interneuron (Bentley, 1975). As a result of the mutation, this neuron is deprived of normal physiological activity without the apparent loss of afferent connections. However, whether the mutation affects the medial giant interneuron directly and whether the afferent contacts are normal in number and morphological appearance remains unknown. In contrast, Haverkamp (1986) argued against a role for afferent activity in inducing initial dendritic outgrowth: dendritic branching patterns on motoneurons in control Xenopus embryos and in those that developed under conditions of continuous immobilization were not significantly different. The present study does not provide information that differentiates between the effect of synaptic activity and afferent contact. Indirect evidence indicates that the ectopic $n$ VIII axons are functional: larvae that develop with one vestibular primordium displaced to the same position as that of the extra vestibular primordium have normal tail flip responses (David and Model, personal communication). In addition, there are no morphological differences between the club terminals on superinnervated M-cells and those on control cells. While a unilateral increase in vestibular synaptic activity on the M-cell may be expected to have behavioral consequences, none were observed: normal balance and orientation were maintained, and tail flips to both sides appeared equal. Blocking vestibular activity without interrupting the formation of afferent contacts may help define the role of synaptic activity in the regulation of dendritic growth.

Direct axodendritic contact may in part mediate the stimulation of dendritic growth. Vaughn et al. (1974) proposed a temporal sequence for the formation of synaptic junctions on growing motoneuron dendrites and suggested that the sequence may be involved in inducing and orienting dendritic develop- ment: as new afferent contacts are formed on dendritic growth cone filopodia, the dendritic growth regions move distally to the zones of contact, and the former growth cone, previously contacted by another afferent, develops the characteristics of a dendrite. The hypothesis further predicts that a region of filopodial membrane becomes fixed in position on the dendrite when it receives afferent contact. Based on this hypothesis, one could argue that some of the dendritic branches on superinnervated M-cells should project rostrally towards the source of ectopic afferents. The proximal branches of the lateral dendrite, however, were all oriented towards the normal site of entry into the medulla of in situ nVIII axons. Thus, the extra vestibular afferents do not appear to orient dendritic growth on the M-cell toward their ectopic origin. To further examine the dendritic branches for evidence of contact-induced growth, the distribution of the vestibular terminals on a superinnervated M-cell was analyzed: labeled and unlabeled terminals were more or less equally distributed on all of the branches (Fig. 12). A different distribution might be predicted when one considers the probable sequence of axon arrival. The supernumerary vestibular nerve enters the medulla approximately $400 \mu \mathrm{m}$ rostral to the in situ one and must travel that distance within the nVIII tract to reach the $\mathrm{M}$-cell. The ectopic axons, therefore, are likely to contact their target later than many of the in situ ones. The labeled (late) terminals, however, are not clustered distally on dendritic branches, or sequestered on a few dendritic branches that were induced to sprout by their late arrival as the above hypothesis would predict. Instead, both labeled and unlabeled terminals are intermixed over all of the dendritic surface. This distribution suggests that afferent contacts can form on the proximal region of a growing dendritic branch and stimulate the addition of membrane there, thus increasing the dendritic surface area and extending the dendritic length.

\section{Summary}

We have shown that unilateral removal of the otic vesicle from axolotl embryos precludes development of the ear, nVIII ganglion, and vestibular nerve. Club endings are absent from the appropriate dendritic branches of the ipsilateral M-cell. Depriving the $\mathrm{M}$-cell of vestibular afferents reduces the dendritic surface in the region that normally receives nVIII terminals. The data also show that implantation of an extra vestibular primordium rostral to the in situ one results in the superinnervation of the ipsilateral M-cell: nVIII axons from both the grafted and in situ ganglia form synapses on the M-cell that are appropriately restricted to the ventral surface and branches of the lateral dendrite. Superinnervation produces a localized enhancement of dendritic branching in the region receiving extra terminals. Afferent innervation clearly has a transsynaptic stimulating effect on the elaboration of dendritic branching patterns. The formation of afferent contacts is essential in regulating the morphogenesis of developing target neurons.

\section{References}

Altman, J., and W. J. Anderson (1972) Experimental reorganization of the cerebellar cortex: I. Morphological effects of elimination of all microneurons with prolonged X-irradiation started at birth. J. Comp. Neurol. 146: 355-406.

Bartelmez, G. W. (1915) Mauthner's cell and the nucleus motorius tegmenti. J. Comp. Neurol. 25: 87-128.

Benes, F. M., T. N. Parks, and E. W. Rubel (1977) Rapid dendritic atrophy following deafferentation: An EM morphometric analysis. Brain Res. 122: 1-13. 
Bentley, D. (1975) Single gene cricket mutations: Effects on behavior, sensilla, sensory neurons, and identified interneurons. Science 187: 760-764.

Bodian, D. (1937) The structure of the vertebrate synapse. A study of the axon endings on Mauthner's cell and neighboring centers in the goldfish. J. Comp. Neurol. 68: 115-159.

Constantine-Paton, M., and M. I. Law (1978) Eye specific termination bands in tecta of three-eyed frogs. Science 202: 639-641.

Gaze, R. M., and S. C. Sharma (1970) Axial differences in the reinnervation of the goldfish optic tectum by regenerating optic nerve fibers. Exp. Brain Res. 10: 171-181.

Goodman, L. A., and P. G. Model (1985) The effect of transsynaptic stimulation on the morphogenesis of the amphibian Mauthner cell. Soc. Neurosci. Abstr. 11: 946.

Harrison, R. G. (1969) Organization and Development of the Embryo, Yale University Press, New Haven, CT.

Haverkamp, L. J. (1986) Anatomical and physiological development of the Xenopus embryonic motor system in the absence of neural activity. J. Neurosci. 6: 1338-1348.

Herrick, C. J. (1914) The medulla oblongata of larval Amblystoma. J. Comp. Neurol. 24: 343-427.

Holloway, R. L. (1966) Dendritic branching: Some preliminary results of training and complexity in rat visual cortex. Brain Res. 2: 393396.

Hoy, R. R., T. G. Nolen, and G. C. Casaday (1985) Dendritic sprouting and compensatory synaptogenesis in an identified interneuron follow auditory deprivation in a cricket. Proc. Natl. Acad. Sci. USA 82: $7772-7776$

Jacoby, J., and C. B. Kimmel (1982) Synaptogenesis and its relation to growth of the postsynaptic cell: A quantitative study of the developing Mauthner neuron in the axolotl. J. Comp. Neurol. 204: 364376.

Katz, L. C., and M. Constantine-Paton (1985) Afferent induced alterations in the dendritic domains of tectal neurons in three-eyed frogs. Soc. Neurosci. Abstr. 11: 804.

Kimmel, C. B., and P. G. Model (1978) Developmental studies of the Mauthner cell. In Neurobiology of the Mauthner Cell, D. S. Faber and H. Korn, eds., pp. 183-220, Raven Press, New York.

Kimmel, C. B., and E. Schabtach (1974) Patterning in synaptic knobs which connect with Mauthner's cell (Ambystoma mexicanum). J. Comp. Neurol. 156: 49-80.

Kimmel, C. B., E. Schabtach, and R. J. Kimmel (1977) Developmental interactions in the growth and branching of the lateral dendrite of Mauthner's cell (Ambystoma mexicanum). Dev. Biol. 55: 244-259.

Larsell, O. (1931) The effect of experimental excision of one eye on the development of the optic lobe and opticus layer in larvae of the tree-frog (Hyla regilla). J. Exper. Zool. 58: 1-20.

Leber, S. M. (1984) Effect of precocious and delayed afferent arrival on synapse localization on the amphibian Mauthner cell. Ph.D. dissertation, Albert Einstein College of Medicine, New York.

Levi-Montalcini, R. (1949) The development of the acoustico-vestibular centers in the chick embryo in the absence of the afferent root fibers and of descending fiber tracts. J. Comp. Neurol. 91: 209-241.

Macagno, E. R. (1977) Abnormal synaptic connectivity following UVinduced cell death during Daphnia development. In Cell and Tissue Interactions, J. W. Lash and M. M. Burger, eds., pp. 293-309, Raven Press, New York.
Marotte, L. R. (1981) Density of optic terminals in half tecta of goldfish with compressed retinotectal projections. Neuroscience 6: 697-702.

Model, P. G. (1978) Aspects of Mauthner cell differentiation in the axolotl, Ambystoma mexicanum. Am. Zool. 18: 253-265.

Model, P. G., and L. $\Lambda$. Goodman (1986) The extent of superinnervation producing transsynaptic stimulating effects on Mauthner cell morphogenesis. Soc. Neurosci. Abstr. 12: 1106.

Model, P. G., and S. Wurzelmann (1982) Vestibular axons form synapses on abnormally derived Mauthner cells. Dev. Brain Res. 3: 123129.

Morest, D. K. (1969) The growth of dendrites in the mammalian brain. Z. Anat. Entwickl.-Gesch. 128: 290-317.

Murphey, R. K., B. Mendenhall, J. Palka, and J. S. Edwards (1975) Deafferentation slows the growth of identified giant interneurons. J. Comp. Neurol. 159: 407-418.

Murphey, R. K., S. E. Johnson, and D. S. Sakaguchi (1983) Anatomy and physiology of supernumerary cercal afferents in crickets: Implications for pattern formation. J. Neurosci. 3: 312-325.

Murray, M., S. Sharma, and M. A. Edwards (1982) Target regulation of synaptic number in the compressed retinotectal projection of goldfish. J. Comp. Neurol. 209: 374-385.

Parks, T. N. (1979) Afferent influences on the development of the brain stem auditory nuclei of the chicken: Otocyst ablation. J. Comp. Neurol. 183: 665-678.

Parks, T. N. (1981) Changes in the length and organization of nucleus laminaris dendrites after unilateral otocyst ablation in chick embryos. J. Comp. Neurol. 202: 47-57.

Peusner, K. D., and D. K. Morest (1977) Neurogenesis in the nucleus vestibularis tangentialis of the chick embryo in the absence of the primary afferent fibers. Neuroscience 2: 253-270.

Piatt, J. (1947) A study of the factors controlling the differentiation of Mauthner's cell in Amblystoma. J. Comp. Neurol. 86: 199-236.

Piatt, J. (1969) The influence of VIIth and VIIIth cranial nerve roots upon the differentiation of Mauthner's cell in Ambystoma. Dev. Biol. 19: 608-616.

Rakic, P. (1972) Extrinsic cytological determinants of basket and stellate cell dendritic pattern in the cerebellar molecular layer. J. Comp. Neurol. 146: 335-354.

Rakic, P., and R. L. Sidman (1973) Organization of cerebellar cortex secondary to deficit of granule cells in weaver mutant mice. J. Comp. Neurol. 152: 133-162.

Shankland, M., D. Bentley, and C. S. Goodman (1982) Afferent innervation shapes the dendritic branching pattern of the medial giant interneuron in grasshopper embryos raised in culture. Dev. Biol. 92: 507-520.

Smith, Z. D. J. (1981) Organization and development of brain stem auditory nuclei of the chicken: Dendritic development in N. Laminaris. J. Comp. Neurol. 203: 309-333.

Vaughn, J. E., C. K. Henrikson, and J. A. Grieshaber (1974) A quantitative study of synapses on motor neuron dendritic growth cones in developing mouse spinal cord. J. Cell Biol. 60: 664-672.

Volkmar, F. R., and W. T. Greenough (1972) Rearing complexity affects branching of dendrites in the visual cortex of the rat. Science 176: 1445-1447. 